\title{
Comunidade de prática em terapia ocupacional para o cuidado em saúde mental na atenção básica em saúde: expectativas e impactos ${ }^{1}$
}

\author{
Taís Quevedo Marcolino ${ }^{a}$, Eliane Nascimento Fantinattib, \\ Alana de Paiva Nogueira Fornereto Gozzi ${ }^{a}$, Maria Fernanda Barboza Cid $^{a}$ \\ aDepartamento de Terapia Ocupacional, Universidade Federal de São Carlos - UFSCar, São Carlos, SP, Brasil. \\ bUniversidade de Campinas - UNICAMP, Campinas, SP, Brasil.
}

\begin{abstract}
Resumo: Introdução: A Atenção Básica em Saúde/ABS caracteriza-se como campo recente de atuação em terapia ocupacional, gerando demandas formativas e necessidade de investigação da prática para construção de corpo de conhecimento próprio a esse contexto. A Comunidade de Prática/CoP vem sendo um referencial utilizado para investigar e promover o desenvolvimento profissional. Assim, foi implementada uma pesquisa-ação em formato de CoP para sete terapeutas ocupacionais atuantes na ABS, que tinham como foco o cuidado em saúde mental. Objetivo: Apresentar as expectativas das profissionais para participarem da $\mathrm{CoP}$ e suas percepções sobre o impacto dessa ferramenta formativa para a produção e a apropriação do cuidado em terapia ocupacional. Método: A CoP organizou-se em encontros presenciais mensais, registrados, transcritos e submetidos à análise temática. Resultados: Foram encontrados dois grandes temas: 1. Expectativas para participação na $\mathrm{CoP}$, com cinco subtemas: CoP como ferramenta para fortalecimento da profissão; Espaço de apoio e continência; Espaço para trocas e para compartilhar informações e conhecimento; Ferramenta para sistematizar e formalizar o trabalho realizado em terapia ocupacional; Oportunidade para entender o cenário de prática e o trabalho realizado; 2. Impactos da CoP, com dois subtemas: CoP como espaço de apoio e continência; Espaço para reflexão sobre a prática. Conclusão: Compreendemos que a Comunidade de Prática se mostrou capaz de fomentar a reflexão sobre a prática, abarcando tanto demandas formativas teórico-metodológicas como questões pessoais e/ou emocionais ligadas ao trabalho.
\end{abstract}

Palavras-chave: Educação Continuada, Terapia Ocupacional, Recursos Humanos em Saúde.

\section{Community of practice in occupational therapy for mental health on primary care: expectations and impacts}

\begin{abstract}
Introduction: Primary Healthcare constitutes a recent field of practice for occupational therapy, creating formative demands and calling for practice investigation to create knowledge inherent to this context. Community of Practice/CoP had been used as theoretical frame to investigate and promote professional development. We implement a $\mathrm{CoP}$ for seven occupational therapists working on mental health primary care. Objective: To present the expectations of professionals about $\mathrm{CoP}$ and their perceptions of the impact of this formative tool for construction and adequacy of the occupational therapy care. Method: The CoP had been organized on monthly meetings, recorded, transcribed and submitted to thematic analysis. Results: We found 2 major themes: 1.Expectations for CoP, with 5 subthemes ( $\mathrm{CoP}$ as a tool for professional strength; Space for support and continence; Space for exchange of knowledge and information; Tool for systematize and formalize occupational therapy practice; Opportunity to understand the practice scenario and work performed) and 2.Impacts of $\mathrm{CoP}$, with 2 subthemes (CoP as support
\end{abstract}

Autor para correspondência: Taís Quevedo Marcolino, Departamento de Terapia Ocupacional, Universidade Federal de São Carlos, Rodovia Washington Luís, Km 235, São Carlos, SP, Brasil, e-mail: taisquevedo@gmail.com

Recebido em Fev. 24, 2016; 1ª Revisão em Maio 21, 2016; 2ª Revisão em Jun. 20, 2016; Aceito em Jul. 7, 2016. 
and continence; Space for reflection on action). Conclusion: Community of Practice revealed itself able to promote reflection on practice, addressing formative needs on methodological and theoretical questions as well as personal and emotional aspects related to work.

Keywords: Continuing Education, Occupational Therapy, Health Manpower.

\section{Introdução}

A Atenção Básica em Saúde (ABS) pode ser considerada um campo de atuação recente para a Terapia Ocupacional no Brasil. Bassi, Malfitano e Bianchi (2012), em trabalho de revisão, indicam que tanto a produção de conhecimento científico como a sistematização das práticas nesse campo ainda são incipientes e a maioria dos trabalhos se relaciona à problemática da pessoa com deficiência física.

$\mathrm{Na}$ Política Nacional da Atenção Básica em Saúde, terapeutas ocupacionais foram inseridos no campo da ABS no âmbito exclusivo dos Núcleos de Apoio à Saúde da Família/NASF (BRASIL, 2006) e, mais recentemente, no consultório na rua e no atendimento domiciliar (BRASIL, 2013), com forte demanda para açôes de cuidado em saúde mental. Entretanto, experiências anteriores, como a realizada pela Prefeitura Municipal de São Paulo, em 1990, indicam a presença de terapeutas ocupacionais nesse campo, em outros formatos de inserção (BASSI; MALFITANO; BIANCHI, 2012).

$\mathrm{O}$ pedido para a equipe multiprofissional que atua em NASF é o de ampliar a abrangência e o escopo das açóes na Atenção Básica, ofertando apoio matricial, em um processo ampliado de compartilhamento de casos e acompanhamento longitudinal (BRASIL, 2006). O Terapeuta Ocupacional é um dos profissionais capacitados para acompanhar e oferecer matriciamento em Saúde Mental (BRASIL, 2011). Entretanto, sendo um campo recente de atuação profissional, abre-se espaço para questionamentos acerca das demandas formativas desses profissionais, tanto na formação inicial (BARBA et al., 2012) como na formação continuada, em processos de educaçáo permanente (BRASIL, 2005).

Franco (2007) discute que grandes recursos e esforços em educação em saúde foram despendidos ao longo do processo de reforma sanitária e psiquiátrica, sem que estes impactos nos serviços tenham sido notados. A ideia de insuficiência do saber dos trabalhadores promoveu propostas educacionais, pensadas por uma instância diretiva e sustentadas na ideia de continuidade de transferência de conhecimentos, para suprir as deficiências da formação. Em contraponto, experiências educacionais que impliquem os trabalhadores com seu processo de trabalho, com suas vivências do cotidiano, de modo a construir novas formas de cuidado e novos modos de significar o trabalho em saúde, vêm ganhando espaço a partir da proposta de Educaçáo Permanente em Saúde - EPS (BRASIL, 2005).

A EPS caracteriza-se como ação estratégica centrada na aprendizagem significativa, a partir da problematização dos processos de trabalho voltada para transformar a organização dos serviços, as práticas de cuidado em saúde e a articulação entre o SUS e as instituições formadoras, abrindo espaço para avaliação e implementação de ferramentas e metodologias educacionais nesse contexto. A reflexão sobre a prática (SCHÖN, 2000) possibilita a tomada de consciência de aspectos implícitos inerentes ao trabalho e permite que novos sentidos possam ser construídos, ampliando compreensôes e ações nos contextos específicos.

Nessa direção, a Comunidade de Prática/CoP (WENGER, 1998) vem sendo um dos referenciais adotados para fomentar processos de educaçáo continuada (CHOI, 2006; CARROLL, 2005; SCHELL; SCHELL, 2008; WELCH; DAWSON, 2006), inclusive no Brasil, para dar conta das complexidades formativas do contexto da ABS, em estratégia do Departamento de Atenção Básica do Ministério da Saúde e do Observatório de Tecnologias em Informação e Comunicação em Sistemas e Serviços de Saúde.

A CoP caracteriza-se por ser um espaço de aprendizagem colaborativa, constituída a partir do engajamento mútuo de pessoas em um empreendimento articulado, pautado na troca de informaçóes e no conhecimento em torno de um repertório comum de saberes. Esta participação ativa constrói e molda os novos conhecimentos, através do diálogo entre os participantes, levando-os, também, a refletir, pesquisar, analisar e avaliar coletivamente suas próprias açôes e seus valores e conhecimentos (WENGER, 1998). É constituída quando pessoas se unem por um interesse compartilhado e desejam realizar mudanças, melhorar práticas já existentes, identificar e obter soluçóes para problemas em um domínio específico de conhecimento.

Além disso, oferece oportunidade para que seus membros reflitam, dialoguem, questionem e 
compartilhem sua sabedoria prática (expertise) e seus recursos. As soluçóes compartilhadas e os insights que emergem das interaçóes entre os participantes geram um "estoque de conhecimento", que é acumulado com o passar do tempo. Os membros da CoP fazem uso desses conhecimentos, concretizando-os em sua prática. Através da interação entre os membros, a CoP promove e sustenta tanto valores tangíveis como não tangíveis, criando uma linguagem comum, fazendo com que conhecimento tácito se torne explícito, criando relacionamentos interpessoais baseados em confiança (LESSER; STORCK, 2001; PREECE, 2004; WENGER, 1998; WESLEY; BUYSSE, 2001).

Com terapeutas ocupacionais, a CoP vem sendo utilizada em processos formativos e investigativos, tanto no Brasil (GALHEIGO; BRAGA, 2012; GALHEIGO et al., 2015; MARCOLINO; LOURENÇO; REALI, 2017) como internacionalmente (HOFFMAN; DESHA; VERRAL, 2011; KINSELLA; WHITEFORD, 2009), indicando ser uma estratégia adequada para melhoria de práticas de cuidado e aprendizagem colaborativa.

Nessa direção, este artigo busca apresentar as expectativas de terapeutas ocupacionais, que atuam na $A B S$ de um município do interior do Estado de Sáo Paulo, para participarem de uma CoP e suas percepçóes sobre o impacto dessa ferramenta formativa para a produção e a apropriação do cuidado em terapia ocupacional em Saúde Mental, no contexto da ABS.

\section{Método}

O contexto de origem da CoP se deu em 2008, com a implantação de um novo currículo pedagógico para o curso de graduação em Terapia Ocupacional da UFSCar (BARBA et al., 2012), em que terapeutas ocupacionais integraram-se ao curso para exercerem papel de preceptoras. Todas as profissionais atuavam na ABS e tinham a maioria de suas açóes de cuidado voltada para a saúde mental. Apenas duas delas estavam inseridas em um NASF e as demais circulavam entre Unidades de Saúde da Família/USF e Unidades Básica de Saúde/UBS de um determinado território administrativo da cidade, com menor apoio de equipe multiprofissional.

Elas mantinham encontros regulares na universidade, cujo foco era o processo de ensino e aprendizagem dos estudantes. Nesses encontros, falavam de suas práticas profissionais e dos desafios enfrentados, mas havia dificuldade de aquele espaço abarcar toda a complexidade necessária para aquela discussão.
Desse modo, para elucidar aspectos gerais e particulares da prática em terapia ocupacional na atenção primária em saúde, com foco no cuidado em saúde mental, foi proposta a construçáo de uma $\mathrm{CoP}$, em uma parceria entre docentes da universidade e as terapeutas ocupacionais preceptoras, que teve início em março de 2013. A pesquisa foi aprovada pelo Comitê de Ética em Pesquisa da UFSCar, sob número 222.028 .

Utilizamos o referencial da pesquisa-ação (DESROCHE, 2006; TOLEDO; GIATTI; JACOBI, 2014), por se tratar de uma proposta de investigaçáo qualitativa, assentada na produção colaborativa de saberes, e em modos participativos, ao incluir todos os envolvidos em relaçóes recíprocas. Observe-se que essa produção colaborativa é voltada para o aprimoramento de práticas, ao construir açóes intencionais que buscam transformaçōes.

A CoP organizou-se em 17 encontros presenciais, mas este artigo tratará dos oito primeiros, entre abril e dezembro de 2013. Os encontros presenciais tiveram por volta de uma hora e meia de duraçáo, e foram realizados em espaços da Universidade, sendo que, em alguns deles, havia indicação de textos para leituras ou exercícios de reflexâo sobre a prática.

Além da equipe de pesquisa - coordenadora do projeto, duas pesquisadoras colaboradoras, duas estudantes de graduação, sendo uma bolsista extensão e uma de iniciação científica -, participaram sete terapeutas ocupacionais, com experiência profissional entre 9 e 28 anos, sendo que cinco delas possuíam cursos de especialização em saúde mental ou saúde da família.

Os encontros foram registrados em áudio e transcritos. As transcriçóes foram utilizadas para elaborar a Crônica do Grupo, caracterizada por ser uma narrativa dos acontecimentos, a partir das interpretaçôes da equipe de pesquisa, que são justificadas por trechos das falas dos participantes. A crônica de cada grupo era lida no início do encontro posterior, em uma proposta tanto de análise de dados preliminar e colaborativa - na medida em que as integrantes da $\mathrm{CoP}$ podiam concordar ou discordar das interpretaçôes e sugerir melhorias ou alteraçôes às interpretaçôes - como de garantia de continuidade da aprendizagem, na medida em que se resgatava o que já havia sido construído (MARCOLINO; REALI, 2016).

As transcrições dos oito encontros presenciais foram submetidas à Análise Temática (MINAYO, 2004), que se constitui como uma variação da Análise de Conteúdo, mantendo-se a crença na significaçáo da regularidade, porém trabalhando com 
os significados em lugar de investir nas tradicionais inferências estatísticas. Em um primeiro momento, após a leitura flutuante, identificados excertos que explicitassem expectativas, desejos, intençôes e objetivos da participação na CoP, e resultados dessa participação. Esses trechos (corpus) foram submetidos à uma nova análise, de modo a identificar núcleos de sentido.

\section{Resultados}

Os resultados indicaram a presença de dois grandes temas:

1. Expectativas para participaçáo na $\mathrm{CoP}$, contendo cinco subtemas:

1.1 CoP como ferramenta para fortalecimento da profissão;

1.2 Espaço de apoio e continência;

1.3 Espaço para trocas e para compartilhar informações e conhecimento;

1.4 Ferramenta para sistematizar e formalizar o trabalho realizado em terapia ocupacional, de modo geral, e pelas terapeutas ocupacionais na Atenção Básica em Saúde, de modo específico;

1.5 Oportunidade para entender o cenário de prática e o trabalho realizado.

2. Impactos Preliminares da CoP, com 2 subtemas:

2.1 Faz sentido vir e compartilhar;

2.2 Espaço para reflexão sobre a prática.

Cada subtema será apresentado com excertos que os justificam, tendo estes sido modificados, apenas, no sentido de remover marcas de oralidade, substituindo-as por termos mais usuais à escrita, sem que, entretanto, tivessem seu significado alterado.

\section{Tema 1: Expectativas para participação na CoP}

Os excertos desse tema indicam os desejos e as intençōes das terapeutas ocupacionais para participarem da CoP. Essa participaçáo exige investimentos tanto de ordem prática, como a disposição de tempo - para além do expediente de trabalho - e o deslocamento para onde os encontros ocorreram, como de ordem abstrata, como a disposição para se abrir a um processo de reflexão sobre sua própria prática profissional e o engajamento em discussóes que exigiam o compartilhamento de conhecimentos e experiências.

\subsection{CoP como ferramenta para fortalecimento da profissão}

As participantes consideraram que estar em uma comunidade formada apenas por terapeutas ocupacionais, que compartilham de cenários de prática similares, seria uma possibilidade para se fortalecer enquanto categoria profissional, bem como fortalecer a profissão e sua atuaçáo no campo da $A B S$, que é um espaço recente de inserção do terapeuta ocupacional.

Acho que éfortalecer mesmo a Terapia Ocupacional. Os cuidados e práticas. Para a gente se unir enquanto carreira, principalmente no município (P1).

Nos fortalecer enquanto terapeutas ocupacionais! (P3).

Como é que está a profissão? E dela se estabelecer e ter uma boa visibilidade e ter um reconhecimento $(\mathrm{P} 2)$.

\subsection{Espaço de apoio e continência}

A CoP é compreendida como um espaço no qual as participantes afirmam encontrar liberdade para conversar tanto sobre a prática profissional como sobre aspectos pessoais. Apresentam a expectativa de que suas demandas sejam acolhidas, discutidas e compreendidas por pessoas que, não apenas compartilham da mesma profissão, mas também atuam em um cenário de prática profissional similar e são capazes de compreender questóes muito específicas desse espaço.

Está sofrido, mas eu acho que nesse momento eu estou precisando. Vai ser muito bom para mim, nesse sentido, ter esse espaço. Até para chorar também, para tudo, para fazer muita coisa. Eu acho que vai ser legal. Eu assino embaixo. Eu sou daqui, me formei aqui, é um prazer (P1).

É meio que um grupo de apoio (P4).

\subsection{Espaço para trocas e para compartilhar informações e conhecimento}

As participantes expressaram a expectativa de que a CoP se constituísse como um local para trocar experiências e informaçóes, e para compartilhar saberes próprios da profissão. 
Isso é uma expectativa minha. Ter um espaço de troca, para compartilhar minhas experiências atuais e de entender o que está acontecendo entre os germens que foram soltos e as construçóes que as pessoas estão fazendo na prática (E2).

Estou curtindo muito. Então eu acho que tudo que vier para somar, eu acho que vai ajudar (P6).

Eu acho que é muito válido a gente sentar para conversar essas coisas, porque é aquela história. A gente acaba pensando de forma individual e acaba se desgastando e nessa troca que a gente vai conseguindo construir alguma coisa (P7).

\subsection{Ferramenta para sistematizar e formalizar o trabalho realizado em terapia ocupacional, de modo geral, e, pelas terapeutas ocupacionais na Atenção Básica em Saúde, de modo específico}

Os excertos a seguir elucidam o desejo de que a CoP possa ser utilizada como ferramenta para produzir sistematização e formalização do trabalho que é realizado. Esta formalização parece se dar em duas direçôes, complementares. A primeira, fala da produção de uma linguagem que facilite a transmissão do que se faz em terapia ocupacional, de modo geral. A outra, no âmbito da $\mathrm{ABS}$, traz à tona a importância de a profissão construir conhecimento e produção científica nesse campo, relativamente recente, e discute-se, inclusive, que o trabalho na ABS parece se sustentar a partir de transferência de conhecimentos das áreas específicas e da saúde coletiva, para esse campo.

Mas acho que o importante do grupo é a gente realmente tentar formalizar mesmo o nosso trabalho (P2).

O grupo surgiu da necessidade da gente. Tinha um questionamento da nossa prática, entâo, por exemplo com relaçấo à saúde mental. No sentido de que a gente faz muitas açóes e essas ações a gente não nomeia, embora a gente tenha algumas metas comuns, a gente não consegue nomear essas açóes. Então, eu acho que surgiu um pouco disso, também, $e$ da gente estar podendo conversar e tentar estabelecer. Uma linguagem comum, alguma coisa que se aproximasse mais, que a gente pudesse falar (P3).

Tentar aprofundar mais na nossa profissão, na Atenção Básica, nesse sentido. Do que escrever, de como lidar, porque às vezes a gente usa uma linguagem técnica que até que ponto a gente discute essas questóes. Uma linguagem técnica que éprópria do terapeuta ocupacional (P1).

\subsection{Oportunidade para entender o cenário de prática e o trabalho realizado}

Ao compartilhar os aspectos da prática a partir da narrativa de eventos cotidianos ou da discussão de recursos que cada terapeuta tem para trabalhar dentro da USF ou da UBS em que estão inseridas, as participantes puderam perceber que, apesar de estarem na Rede de Atenção em Saúde do mesmo Município, as características da prática de cada uma estava muito ligada aos aspectos de cada território. Diante de uma multiplicidade de aspectos e questóes, manifestaram o desejo de que a CoP pudesse ser uma oportunidade para compreender melhor a prática da terapia ocupacional na ABS, mas com as particularidades de cada território.

Entender o nosso trabalho. Porque cada uma faz uma coisa. A gente acaba náo sabendo muito, o que uma faz, o que outra faz... Eu acho que eu e a P1, a gente tem mais contato porque a gente trabalha ali na mesma comunidade. Eu acho que fica mais fácil... Mas eu acho que a gente está pensando sobre terapia ocupacional em cima das nossas atividades.

\section{Tema 2: Impactos iniciais da CoP}

$\mathrm{Na}$ análise dos oito primeiros encontros, foi possível identificar, ainda que preliminarmente, dois subtemas que parecem indicar impactos percebidos pelas participantes e que se aproximam de expectativas apresentadas anteriormente.

\subsection{CoP como espaço de apoio e continência}

A CoP foi considerada como um espaço de continência e apoio. As participantes afirmaram que encontraram abertura para colocar suas demandas e realizar "trocas afetivas" com as demais, como um espaço subjetivo, no qual as participantes afirmaram sentirem-se bem, mesmo com a dificuldade de se deslocar até a universidade após o expediente de trabalho.

Eu tenho muita dificuldade para vir, mas depois que eu estou aqui é tão bom! (P4). 


\section{Eu partilho disso! (P3).}

Olha, vou te falar... Para mim, é muito difícil de vir. Mas é bom, a gente compartilhar, mas é dificil para vir (P4).

Estou tão feliz de estar aqui hoje! (P1).

Estamos felizes porque você está aqui hoje! (P2).

\subsection{Espaço para reflexão sobre a prática}

As participantes consideraram que o grupo é realmente um espaço para a reflexão sobre a prática. Essa reflexão foi disparada, principalmente, tanto pelos textos oferecidos como no movimento de "olhar" para os relatos da prática de outras participantes ou de si mesmas. Em ambos os casos, considerou-se possível fazer uma reflexão crítica acerca dos fatos apresentados e se aproximar ainda mais da multiplicidade de práticas realizadas por terapeutas ocupacionais no contexto da ABS, com foco nas açóes de cuidado no campo da Saúde Mental.

Mas eu acho que ébom, porque faz a gente pensar. Porque são açôes que a gente tem na nossa prática corriqueira e a gente nem pensa o porquê a gente está fazendo isso. É uma coisa tão habitual, e a gente acaba não parando pra pensar mesmo (P1).

$\dot{E}$ a gente reconhecer essas práticas, essas açōes. O quanto está subliminar para a gente também (P2).

É um momento para isso que a gente tem para parar para pensar (P1).

\section{Discussão}

A CoP foi reconhecida como um espaço de apoio e continência, o que nos possibilitou dar visibilidade a essa necessidade das profissionais, destacando que a produção coletiva foi sustentada por relaçôes afetivas. Ressaltamos que as participantes já se constituíam como grupo em outros espaços, como terapeutas ocupacionais do município, como preceptoras de estudantes. Essa história pregressa emerge como um elemento a se considerar para avaliar a produçáo grupal, pois pode atuar como inibidor ou facilitador para a criação de relações de confiança (LESSER; STORCK, 2001; PREECE, 2004; WENGER, 1998; WESLEY; BUYSSE, 2001). O fato foi que, nesse caso, pareceu favorecer a formação de identidade grupal e o trabalho colaborativo, pois, para Grossman,
Winenburg e Woolworth (2001), uma comunidade de aprendizagem profissional demora algum tempo para se estabelecer.

Espaços como esse são considerados estratégias de enfrentamento ante às dificuldades vivenciadas por terapeutas ocupacionais, destacando a importância do estabelecimento de redes de apoio, inclusive apoio emocional, o que favorece o reconhecimento das dificuldades e potencializa o profissional para sua superação (BOTTINELLI; NABERGOI, 2004; LLOYD; BASSETT, 2001).

Assim, o reconhecimento das dificuldades enfrentadas, que se colocaram como expectativas e motivações para o trabalho na $\mathrm{CoP}$, abarcou questôes que ainda demandam investimento, tanto no cenário brasileiro como internacional, e perpassou questôes da Terapia Ocupacional, de modo geral - como o desejo do fortalecimento da profissáo e de construir uma linguagem que seja comum -, e no contexto específico da ABS.

A fragilidade no reconhecimento da profissão é um dilema clássico da Terapia Ocupacional, ainda presente na contemporaneidade (AAS; KINN, 2009; CARVALHO, 2010; ROGERS; DODSON, 1988; GALHEIGO; TESSUTO, 2010; JUNS; LANCMAN, 2011; LLOYD; BASSETT, 2001; KORNBLAU, 2004; STILL; SCANLAN, 2013). Assim, o desejo pelo fortalecimento da Terapia Ocupacional se apresentou como um grande motivador para as participantes, $o$ que indica ainda que, embora já se tenha havido a consolidação da profissão no Brasil, no que tange à formação graduada (LANCMAN, 1998) e à inserção de profissionais nos serviços públicos, através de regulamentações ministeriais (BEIRÃO; ALVES, 2010), os profissionais ainda vivenciam dilemas de conhecimento e reconhecimento profissional no cotidiano do trabalho, nos quais investem esforços para resolver (WILDING; WHITEFORD, 2007).

Essa expectativa vem atrelada ao desejo de formalizar e sistematizar o trabalho, o que abre espaço para a construção de uma postura investigativa nas profissionais participantes (MARCOLINO, 2014) e demonstra que esse poderia ser o caminho para ganhar maior reconhecimento externo e tranquilidade interna, para falar do que se faz, como também discutem Galheigo et al. (2015). Essa questão náo nos parece ser específica da ABS, ou mesmo da Saúde Mental, mas do campo da Terapia Ocupacional, sendo interpelado por diferentes problemas, como a tensão com o modelo biomédico (MATTINGLY; FLEMING, 1994), a ligação a diferentes paradigmas e o uso de teorias emprestadas de outras disciplinas (BENETTON, 2005; IKIUGU, 2007; REITZ; PIZZI; SCAFFA, 2010). 
Em relaçáo à $A B S$, dado que se constitui como um campo de prática relativamente recente, e pelo fato de que o cuidado em saúde mental ainda é pouco sistematizado (BASSI; MALFITANO; BIANCHI, 2012), este constituiu outro ponto motivador para o trabalho na CoP. As participantes levantaram questionamentos sobre a aplicabilidade dos conhecimentos adquiridos em outros campos de atuação da profissão (Reabilitação Física, Saúde Mental, Saúde Coletiva) e quais ajustes ou novos conhecimentos sáo produzidos para atuaçáo profissional na $A B S$, e dispuseram-se, ainda, a compartilhar particularidades do trabalho e do território no qual estão inseridas.

Assim, o processo de reflexão sobre a prática foi reconhecido como importante e potente, um espaço separado das demandas do dia a dia, que possibilita pensar e reconhecer o que está subliminar e que, cotidianamente, não se percebe, como já havíamos analisado em trabalhos anteriores (MARCOLINO; REALI, 2010, 2016).

Schön (2000) discute que esse processo é o que sustenta a construçấo de conhecimento prático, pois, reconhecendo a prática como um campo imerso em situaçôes complexas e singulares, não se trata da aplicaçáo de teorias, mas sim da produçấo de conhecimento que lhe é próprio.

Desse modo, a estratégia da CoP vai ao encontro do que se almeja para a formação profissional contemporânea, tanto inicial como continuada, ou educação permanente, pois possibilita que os sujeitos envolvidos definam problemas de seu interesse, centrados em processos de trabalho, e utilizem tais processos como fontes de reflexão, avaliação e revisão de modos de compreensão e, consequentemente, prática, entendendo que esse tipo de reflexão implica em açôes intencionais posteriores (RODGERS, 2002).

\section{Conclusão}

A CoP se constituiu, desde o início, como um espaço propício ao acolhimento de demandas emocionais ligadas ao trabalho e às dificuldades encontradas no dia a dia das participantes. Consideramos que isso foi facilitado pelo fato de esse grupo de profissionais já ter ligaçôes prévias e relaçôes produtivas com a universidade.

Desse modo, o "espaço de apoio e continência" surgiu tanto como uma expectativa para participação como um resultado preliminar da participação na $\mathrm{CoP}$, o que nos leva a refletir que tanto a necessidade de estabelecer relaçóes de confiança como de compartilhar dificuldades da prática profissional cotidiana são aspectos relevantes para participação nesse tipo de proposta.

Muitas vezes, a exposição destes dilemas foi capaz de gerar reflexôes mais globais sobre as ações profissionais; tal exposição também é encontrada enquanto expectativa e impacto da ferramenta. Essas reflexóes são capazes de satisfazer a proposta da construção coletiva de conhecimento, tornando a ferramenta eficaz no sentido da aprendizagem colaborativa.

A ABS se apresenta como um campo de atuaçáo aberto para investigaçôes, no sentido da construção de um corpo de conhecimento em Terapia Ocupacional, de fato, voltado para essa nova realidade de prática. Terapeutas ocupacionais que atuam nesse contexto ainda encontram-se instrumentalizados de saberes obtidos de diferentes campos de conhecimento, aprendidos na formação inicial ou experiências prévias em outros campos. Assim, mesmo profissionais experientes, como os participantes desta pesquisa-ação, quando atuam na $A B S$, podem ser considerados iniciantes, o que implica em novas configuraçóes de saberes e práticas (SCHÖN, 2000).

Assim, a Comunidade de Prática emerge como ferramenta para a formalização do trabalho na ABS, sendo capaz de abarcar os conhecimentos prévios e a experiência de cada um de seus participantes na produção de novos saberes, no encontro das necessidades formativas enquanto estratégia de EPS, em toda a complexidade que esse processo envolve. Possibilita-se, inclusive, a eleição de temas de interesse para discussão, que sejam pertinentes ao contexto de prática, ou mesmo a exposiçáo de questóes emocionais/pessoais que perpassam a atuação profissional.

Compreendemos a limitação do estudo, por se tratar de uma experiência singular de pesquisa-ação, mas esperamos que a discussão deste trabalho possa tanto enriquecer a construçáo de processos de formação, inicial e continuada, voltada para essa temática, como disparar pesquisas que contribuam para compreensão das particularidades da prática de terapia ocupacional na $\mathrm{ABS}$, em especial quando o cuidado se dá em açôes de fomento à saúde mental.

\section{Referências}

AAS, R. W.; KINN, L. G. Occupational therapist's perception of their practice: a phenomenological study. Australian Occupational Therapy Journal, Victoria, v. 56, n. 2, p. 112-121, 2009. 
BARBA, P. C. S. D. et al. Formação inovadora em Terapia Ocupacional. Interface-Comunicação, Saúde, Educação, Botucatu, v. 16, n. 42, p. 829-842, 2012.

BASSI, B. C.; MALFITANO, A. P. S.; BIANCHI, P. C. O terapeuta ocupacional na atenção básica em saúde: a representatividade em revistas e nos congressos brasileiros. Cadernos de Terapia Ocupacional da UFSCar, São Carlos, v. 20, n. 3, p. 443-454, 2012.

BEIRÃO, R. O. S.; ALVES, C. K. A. Terapia Ocupacional no SUS: Refletindo sobre a normatização vigente. Cadernos de Terapia Ocupacional da UFSCar, São Carlos, v. 18, n. 3, p. 231-246, 2010.

BENETTON, M. J. Além da opinião: uma questão de investigação para a historicização da Terapia Ocupacional. Revista CETO, Sáo Paulo, v. 9, n. 9, p. 4-8, 2005.

BOTTINELLI, M. M.; NABERGOI, M. Saúde do terapeuta ocupacional como trabalhador. Síndrome de Burnout: eixo para pensar nas relaçóes entre reflexividade, pesquisa e prática. In: LANCMAN, S. Saúde, Trabalho e Terapia Ocupacional. São Paulo: Roca, 2004. p. 187-207.

BRASIL. Ministério da Saúde. Secretaria de Gestão do Trabalho e da Educação na Saúde. Departamento de Gestão da Educação na Saúde. A educação permanente na roda: pólos de educação permanente em saúde: conceitos e caminhos a percorrer. Brasília: Ministério da Saúde, 2005 .

BRASIL. Ministério da Saúde. Politica Nacional da Atenção Básica. Brasília: Ministério da Saúde, 2006. Disponível em: <http://bvsms.saude.gov.br/bvs/publicacoes/ politica_nacional_atencao_basica_2006.pdf $>$. Acesso em: 02 maio 2014.

BRASIL. Ministério da Saúde. Guia prático de matriciamento em Saúde Mental. Brasília: Ministério da Saúde, 2011. Disponível em: <http://bvsms.saude.gov.br/bvs/ publicacoes/guia_pratico_matriciamento_saudemental. pdf>. Acesso em: 28 set. 2015.

BRASIL. Ministério da Saúde. Passo a passo das açōes do Departamento de Atençâo Básica. Brasília: Ministério da Saúde, 2013. Disponível em: <http://189.28.128.100/ dab/docs/portaldab/documentos/passo_a_passo_dab. pdf $>$. Acesso em: 29 set. 2015.

CARROLL, D. Learning through interactive talk: a school-based mentor teacher study group as a context for professional learning. Teaching and Teacher Education, Philadelphia, v. 21, n. 5, p. 457-473, 2005.

CARVALHO, C. R. A. A atuação dos terapeutas ocupacionais em unidades públicas de saúde da cidade do Rio de Janeiro. 2010. 82 f. Dissertação (Mestrado em Ciências) - Escola Nacional de Saúde Pública Sergio Arouca, Rio de Janeiro, 2010.

CHOI, M. Communities of practice: an alternative learning model for knowledge creation. British Journal of Educational Technology, West Sussex, v. 37, n. 1, p. 143146, 2006.
DESROCHE, H. Pesquisa-ação: dos projetos de autores aos projetos de atores e vice-versa. In: THIOLLENT, M. Pesquisa-ação e Projeto Cooperativo na Perspectiva de Henri Desroche. São Carlos: EDUFSCar, 2006. p. 33-68.

FRANCO, T. B. Produção do cuidado e produção pedagógica: integração de cenários do sistema único de saúde no Brasil. Interface - Comunicação, Saúde, Educação, Botucatu, v. 11, n. 23, p. 427-438, 2007.

GALHEIGO, S. M. et al. Comunidade de prática em terapia ocupacional: a avaliação do processo pelos participantes e pelos pesquisadores. Cadernos de Terapia Ocupacional da UFSCar, São Carlos, v. 23, n. 3, p. 463-474, 2015.

GALHEIGO, S. M.; BRAGA, C. P. Creating a community of practice: preliminary findings of an innovative approach. In: CONGRESS OF OCCUPATIONAL THERAPY, 9., 2012, Estocolmo. Proceedings... Estocolmo: COTEC/Swedish Association of Occupational Therapists, 2012. p. 1

GALHEIGO, S. M.; TESSUTO, L. A. A. Trajetórias, percepçóes e inquietaçóes de terapeutas ocupacionais do Estado de São Paulo no âmbito das práticas da terapia ocupacional no hospital. Revista de Terapia Ocupacional da Universidade de São Paulo, São Paulo, v. 21, n. 1, p. 23-32, 2010.

GROSSMAN, P.; WINENBURG, S.; WOOLWORTH, S. Toward a theory of teacher community. Teachers College Record, New York, v. 103, n. 6, p. 942-1012, 2001.

HOFFMAN, T.; DESHA, L.; VERRALL, K. Evaluating an online occupational therapy community of practice and its role in supporting occupational therapy practice. Australian Occupational Therapy Journal, Victoria, v. 5, n. 58, p. 337-345, 2011

IKIUGU, M. N. Psychosocial Conceptual Practice Models in Occupational Therapy: Building Adaptive Capability. St. Louis: Mosby Elsevier, 2007.

JUNS, A. G.; LANCMAN, S. O trabalho interdisciplinar no CAPS e a especificidade do trabalho do terapeuta ocupacional. Revista de Terapia Ocupacional da Universidade de São Paulo, São Paulo, v. 22, n. 1, p. 27-35, 2011.

KINSELLA, E. A.; WHITEFORD, G. E. Knowledge generation and utilisation in occupational therapy: towards epistemic reflexivity. Australian Occupational Therapy Journal, Victoria, v. 56, n. 4, p. 249-258, 2009.

KORNBLAU, B. A vision for our future. The American Journal of Occupational Therapy, Bethesda, v. 58, n. 1, p. 9-14, 2004.

LANCMAN, S. Réflexions sur la constitution du champ de l'ergothérapie au Brésil. Journal d)Ergothérapie, Paris, v. 20 , n. 2, p. 85-89, 1998.

LESSER, E. L.; STORCK, J. Communities of Practice and organizational performance. IBM Systems Journal, New York, v. 40, n. 4, p. 831-841, 2001. 
LLOYD, C.; BASSETT, H. Occupational Therapy in Mental Health: managing stress and burnout. British Journal of Occupational Therapy, West Sussex, v. 64, n. 8, p. 406-411, 2001.

MARCOLINO, T. Q. Reflexôes sobre a investigação do raciocínio clínico em terapia ocupacional em saúde mental: o caso do Método Terapia Ocupacional Dinâmica. Cadernos de Terapia Ocupacional da UFSCar, São Carlos, v. 22, n. 3, p. 635-642, 2014. http://dx.doi. org/10.4322/cto.2014.086.

MARCOLINO, T. Q.; LOURENÇO, G. F.; REALI, A. M. M. R. "Isso eu levo para a vida": aprendizagem da prática profissional em uma Comunidade de Prática. Interface - Comunicação, Saúde, Educação, Botucatu, v. 21, n. 61, p. 1-10, 2017. No prelo. http://dx.doi. org/10.1590/1807-57622016.0099.

MARCOLINO, T. Q.; REALI, A. M. M. R. El trabajo del mentor. Análisis de los feedbacks de diarios reflexivos a lo largo de un proceso de mentoría en grupo. Revista Iberoamericana de Educación, Madrid, v. 52, n. 6, p. $1-12,2010$.

MARCOLINO, T. Q.; REALI, A. M. M. R. Crônicas do grupo: ferramenta para análise colaborativa e melhoria da reflexão na pesquisa-ação. Interface - Comunicação, Saúde, Educação, Botucatu, v. 20, n. 56, p. 65-76, 2016. http://dx.doi.org/10.1590/1807-57622015.0257.

MATTINGLY, C.; FLEMING, M. H. Clinical Reasoning: forms of inquiry in a therapeutic process. Philadelphia: F. A. Davis Company, 1994.

MINAYO, M. C. S. O desafio do conhecimento: pesquisa qualitativa em saúde. São Paulo: HUCITEC, 2004.

PREECE, J. Etiquette, empathy, and trust in communities of practice: stepping-stones to social capital. Journal of Universal Computer Science, Austria, v. 10, n. 2, p. 294-302, 2004.

REITZ, S. M.; PIZZI, M. A.; SCAFFA, M. E. Evaluation principles in Heatlh Promotion Practice. In: SCAFFA, M. E.; REITZ, S. M.; PIZZI, M. A. Occupational
Therapy in the Promotion of Hetalth and Wellness. Philadelphia: F.A Davis Company, 2010. p. 157-172.

RODGERS, C. Defining reflection: another look at John Dewey and reflective thinking. Teachers College Record, New York, v. 104, n. 4, p. 842-866, 2002.

ROGERS, J. C.; DODSON, S. C. Burnout in Occupational Therapists. The American Journal of Occupational Therapy, Bethesda, v. 42, n. 12, p. 787-792, 1988.

SCHELL, B. A. B.; SCHELL, J. W. Clinical and Professional Reasoning in Occupational Therapy. Philadelphia: Wolters Klumer, 2008.

SCHÖN. D. Educando o profissional reflexivo. Porto Alegre: Artmed, 2000.

STILL, M.; SCANLAN, J. N. Job satisfaction, burnout and turnover intention in occupational therapists working in mental health. Australian Occupational Therapy Journal, Victoria, v. 60, n. 5, p. 310-318, 2013.

TOLEDO, R. F.; GIATTI, L. L.; JACOBI, P. R. A pesquisa-ação em estudos interdisciplinares: análise de critérios que só a prática pode revelar. Interface - Comunicação, Saúde, Educação, Botucatu, v. 18, n. 51, p. 633 646, 2014.

WELCH, A.; DAWSON, P. Closing the gap: collaborative learning as a strategy to embed evidence within occupational therapy practice. Journal of Evaluation in Clinical Practice, New Jersey, v. 12, n. 2, p. 227-238, 2006.

WENGER, E. Communities of practice learning, meaning and identity. Cambridge: Cambridge University Press, 1998.

WESLEY, P.; BUYSSE, V. Communities of practice: expanding professional roles to promote reflection and shared inquiry. Topics in Early Childhood Education, Washington, v. 21, n. 2, p. 114-123, 2001.

WILDING, C.; WHITEFORD, G. Occupation and occupational therapy: Knowledge paradigms and everyday practice. Australian Occupational Therapy Journal, Victoria, v. 54, n. 3, p. 185-193, 2007.

\section{Contribuição dos Autores}

Taís foi responsável pela concepção do texto e análise dos dados e discussão. Eliane foi responsável pela organização das fontes e análise dos dados. Alana contribuiu com a discussão do texto e Maria Fernanda foi responsável pela revisão do texto. Todas as autoras aprovaram a versão do texto.

\section{Fonte de Financiamento}

PIBIC/CNPq/UFSCar; PROEX/UFSCar 23112.003780/2012-20; 23112.004575/2013-62.

\section{Notas}

1 Trata-se de resultado de pesquisa de Iniciação Científica, inserida em um projeto maior de pesquisa-ação, ofertado também como atividade de extensão universitária. A pesquisa foi aprovada pelo Comitê de Ética sob parecer no 22.028. 